\title{
INCLUSÃO NO ENSINO SUPERIOR: UM PROCESSO EM PAUTA NA UNIVERSIDADE FEDERAL DE JUIZ DE FORA - UFJF
}

\author{
INCLUSIÓN EN LA EDUCACIÓN SUPERIOR: UN PROCESO EN PAUTA EN LA \\ UNIVERSIDAD FEDERAL DE JUIZ DE FORA - UFJF
}

\section{INCLUSION IN HIGHER EDUCATION: A PROCESS ON THE AGENDA AT THE FEDERAL UNIVERSITY OF JUIZ DE FORA - UFJF}

\author{
Cassiano Caon AMORIM ${ }^{1}$ \\ Katiuscia C. Vargas ANTUNES ${ }^{2}$ \\ Mylene Cristina SANTIAGO ${ }^{3}$
}

\begin{abstract}
RESUMO: O artigo aqui apresentado tem como proposta relatar e refletir sobre como os processos de inclusão vêm sendo construídos na Universidade Federal de Juiz de Fora (UFJF). Entre as iniciativas que a UFJF tem priorizado, destacaremos a criação do Núcleo de Apoio à Inclusão (NAI) e, mais pontualmente, a criação de uma modalidade de bolsa de treinamento profissional (TP) voltada para o assessoramento ao NAI e o acompanhamento acadêmico dos estudantes com deficiência. Tal projeto tem nos trazido muitos desafios e, ao mesmo tempo, revelado o quanto é importante que os estudantes que não possuem deficiência se vejam como promotores de ações inclusivas e, com os estudantes com deficiência, construam uma universidade mais inclusiva para todos. Para demonstrar o que acabamos de afirmar, utilizaremos alguns trechos das cartas de intenção que os estudantes escreveram para concorrer às bolsas como elementos discursivos importantes para ilustrar a relevância da necessidade de ampliar as práticas inclusivas no interior das universidades e outras instituições de ensino. Os textos dos estudantes revelam aspectos essenciais sobre diferentes nuances da inclusão. Os resultados desta análise apontam que a UFJF, por meio do NAI, vem construindo uma experiência com potencial para desencadear culturas, políticas e práticas de inclusão na comunidade acadêmica, tendo os estudantes como principais protagonistas.
\end{abstract}

PALAVRAS-CHAVE: Inclusão educacional. Ensino Superior. Treinamento profissional.

RESUMEN: El artículo presentado aquí tiene como objetivo informar y reflexionar sobre cómo se han construido los procesos de inclusión en la Universidad Federal de Juiz de Fora (UFJF). Entre las iniciativas que UFJF ha priorizado, destacaremos la creación del Centro de Apoyo para la Inclusión (NAI) y, más específicamente, la creación de una modalidad de beca de capacitación profesional (TP) dirigida a asesorar el NAI y el seguimiento académico.

\footnotetext{
${ }^{1}$ Universidade Federal de Juiz de Fora (UFJF), Juiz de Fora - MG - Brasil. Professor do Departamento de Educação da UFJF. Professor do Programa de Pós-Graduação em Educação (PPGE/UFJF) e do Programa de Pós-Graduação em Gestão e Avaliação da Educação Básica (PPGP/UFJF). Atualmente é Pró-Reitor Adjunto de Graduação na UFJF. E-mail: cassianoamorim@ hotmail.com

${ }^{2}$ Universidade Federal de Juiz de Fora (UFJF), Juiz de Fora - MG - Brasil. Professora do Departamento de Educação da UFJF e do Programa de Pós-Graduação em Gestão e Avaliação da Educação Pública (PPGP/CAED/UFJF). Pesquisadora do Núcleo de Estudos e Pesquisa em Educação e Diversidade (NEPEDUFJF) e do Observatório Internacional de Inclusão, Interculturalidade e Inovação Pedagógica. ORCID: https://orcid.org/0000-0003-2861-551X. E-mail: katiuscia.vargas@ hotmail.com

${ }^{3}$ Universidade Federal de Juiz de Fora (UFJF), Juiz de Fora - MG - Brasil. Professora do Departamento de Educação da UFJF e do Programa de Pós-Graduação em Educação da UFF. Pesquisadora do Observatório Internacional de Inclusão, Interculturalidade e Inovação Pedagógica. ORCID: https://orcid.org/0000-0003-27698421. E-mail: mylenesantiago87@gmail.com
} 
estudiantes con discapacidad Tal proyecto nos ha traído muchos desafíos y al mismo tiempo reveló la importancia de que los estudiantes sin discapacidades se vean a sí mismos como promotores de una acción inclusiva y, con los estudiantes con discapacidades, para construir una universidad más inclusiva para todos. Para demostrar lo que acabamos de decir, utilizaremos algunos extractos de las cartas de intención que los estudiantes escribieron para solicitar becas como elementos discursivos importantes para ilustrar la relevancia de la necesidad de ampliar las prácticas inclusivas dentro de las universidades y otras instituciones educativas. Los textos de los estudiantes revelan aspectos esenciales sobre diferentes matices de inclusión. Los resultados de este análisis indican que la UFJF, a través de NAI, ha estado construyendo una experiencia con potencial para desencadenar culturas, políticas y prácticas de inclusión en la comunidad académica, con los estudiantes como protagonistas principales.

PALABRAS CLAVE: Inclusión educativa. Enseñanza superior. Formación profesional.

ABSTRACT: The paper analyzes how to set up the inclusion of private criteria in the context of educational policy educational system management materialized by the Ministry of Education of Mato Grosso do Sul (SED/MS) from 2007 to 2013. He worked with bibliographical and documentary research. It was found to replace the democratic management by another logical management guided by goals in organizational scale aimed at Total Quality Education. Thus, SED/MS sought suit management model, which is based on the principle of efficiency, with an emphasis on results through the implementation of the proposed "Education for Success". This proposal has changed, for example, procedures for the provision of post of school principal as establishing assessment systems through occupational certification as an instrument of meritocracy and competition for the director function of state schools. The results of this analysis point out that the UFJF, through the NAI, has been building an experience with potential to unchain cultures, policies and practices of inclusion in the academic community, with students as main protagonists.

KEYWORDS: Educational inclusion. University graduate. Professional training.

\section{Apresentação}

Iniciamos o presente ensaio assumindo a posição de que escrever sobre os processos de inclusão de pessoas com deficiência (PCD) no Ensino Superior constitui-se um desafio. Ao contrário do que ocorreu na Educação Básica, em que os debates, políticas e práticas relacionados à inclusão vêm sendo consolidados, pelo menos desde 1990. No Ensino Superior, tal realidade ganha destaque nos anos 2000, em particular, após a aprovação de políticas afirmativas que preveem reserva de vagas nas universidades e institutos federais para pessoas com deficiência. Um marco legal desse processo ocorreu em 28 de dezembro de 2016, com a promulgação da Lei 13.409/2016, que reserva vagas para PCD nas instituições de Ensino Superior e nos cursos técnicos de nível médio das instituições federais de ensino.

Mesmo configurando-se um desafio, propusemo-nos neste artigo a contribuir para o debate em torno da inclusão de PCD no Ensino Superior, relatando e refletindo sobre como os 
processos de inclusão vêm sendo construídos na Universidade Federal de Juiz de Fora (UFJF). Entre as iniciativas que a UFJF tem priorizado, destacaremos no decorrer do texto a criação do NAI e, mais especificamente, a criação de uma modalidade de bolsa de treinamento profissional voltada para o assessoramento ao NAI e o acompanhamento acadêmico dos estudantes com deficiência. Embora tais processos tenham ganhado força em 2017, exatamente em função da Lei 13.409/2016, existe uma história que antecede esse momento que merece ser resgatada. Antes, porém, é importante trazermos algumas reflexões sobre a temática da inclusão educacional de PCD do Ensino Superior.

Entendemos que, para que a inclusão educacional de PCD seja plenamente alcançada, pelo menos três princípios básicos devem ser resguardados, a saber: o acesso, a permanência e a participação com qualidade nos processos educativos que se constroem no contexto da Educação Básica e do Ensino Superior. No que se refere ao acesso, as normatizações sobre a inclusão de estudantes PCD nas universidades começaram a ser formuladas nacional e internacionalmente há cerca de quatro décadas. O tema entrou em pauta nas discussões relacionadas à inclusão em educação de diferentes países que integram a Organização das Nações Unidas (ONU). Um marco histórico desse processo foi a Declaração dos Direitos das Pessoas com Deficiência de 1975, que já acenava para a garantia do direito à educação das PCD, nos diferentes níveis de ensino. Após a Declaração de 1975, movimentos e documentos em prol da inclusão no âmbito nacional e internacional, em particular entre os anos de 1980 e 1990, foram acontecendo, com destaque para: a Conferência Mundial de Educação para Todos (1990); a Conferência de Salamanca, da qual resultou a Declaração de Salamanca: sobre princípios, políticas e práticas na área das necessidades educativas especiais (1994); e a Declaração Mundial sobre Educação Superior no Século XXI: visão e ação (1998) (CABRAL; MELO, 2017).

Tais marcos históricos e legais contribuíram significativamente para que o acesso das PCD aos diferentes níveis de ensino fosse ampliado, de maneira que no contexto brasileiro é possível afirmar que na Educação Básica a pauta em discussão nos sistemas de ensino já avançou em relação ao acesso e tem se voltado para pensar práticas inclusivas que garantam a permanência e a participação dos estudantes com deficiência nas escolas. Com a chegada de meninas e meninos com deficiência e outras necessidades especiais nas escolas, foram impulsionadas mudanças no seu cotidiano; mudanças que passam por diferentes dimensões, impactando o trabalho de gestores, educadores e demais atores que atuam na educação.

A exemplo do que ocorreu na Educação Básica, a chegada de estudantes com deficiência nas universidades tem desafiado a cultura institucional desses espaços, bem como as práticas educativas e de gestão que historicamente foram construídas no contexto do 
Ensino Superior. Gestores, docentes e demais profissionais que trabalham nesse nível de ensino são desafiados, cotidianamente, a lidar com a diversidade que habita as universidades. Diferenças culturais, socioeconômicas, étnicas, raciais, de gêneros, de credos, entre outras, têm feito com que a cultura institucional das universidades seja repensada. Somada a tantas diferenças, não podemos nos esquivar do fato de que a ampliação do acesso das PCD no Ensino Superior constitui, na atualidade, um dos maiores desafios que tais instituições vêm enfrentando.

Questões relacionadas à acessibilidade arquitetônica e pedagógica, barreiras atitudinais e de comunicação, ausência de um serviço de atendimento educacional especializado, falta de formação dos docentes para lidar com os estudantes com deficiência em sala de aula, questionamentos sobre a capacidade de esses estudantes exercerem a profissão para a qual estão se formando e muitas outras têm sido constantemente levantadas por profissionais que atuam no Ensino Superior. Por vezes, tal realidade provoca em alguns desses profissionais uma profunda angústia e uma sensação de rejeição ao fato de esses estudantes frequentarem o Ensino Superior. Por outras, tem mobilizado muitos profissionais a buscar mais conhecimento e formação para adaptar suas práticas de maneira a eliminar as barreiras à aprendizagem e participação. O fato é que, de uma maneira ou de outra, as mudanças vêm se desenhando, ainda que timidamente, para não só garantir o acesso, mas também a permanência dos estudantes com deficiência no Ensino Superior.

Recorrendo à legislação vigente no Brasil, ressaltamos que a Política Nacional de Educação Especial na Perspectiva da Educação Inclusiva - PNEEPEI (2008) e a Convenção sobre os Direitos das Pessoas com Deficiência - Lei Brasileira de Inclusão (Lei 13.146/2015) enfatizam a garantia de acesso das PCD aos diferentes níveis de ensino.

Com a ampliação do acesso, vem o desafio de garantir a permanência e a participação com qualidade das PCD nos processos educacionais e na vida universitária como um todo, não apenas nas atividades de ensino, mas também nas atividades de pesquisa e extensão. Esse desafio tem mobilizado muitas instituições de Ensino Superior, entre elas a UFJF, a repensar a sua realidade, construindo culturas, políticas e práticas inclusivas que, ao beneficiarem os estudantes com deficiência, acabam por tornar o ambiente universitário mais inclusivo e democrático para todos, independentemente da condição de ser uma pessoa com deficiência ou não.

Recorrendo à PNEEPEI (2008), cabe explicitar o que esse documento apresenta com relação à inclusão no Ensino Superior: 
No Ensino Superior, a transversalidade da Educação Especial se realiza por meio de ações que promovam o acesso, a permanência e a participação dos estudantes. Tais ações envolvem o planejamento e a organização de recursos e serviços a fim de promover a acessibilidade arquitetônica, nas comunicações, nos sistemas de informação, nos materiais didáticos e pedagógicos, os quais devem ser colocados à disposição nos processos seletivos e no desenvolvimento de todas as atividades que envolvem o ensino e a pesquisa (BRASIL, 2008, p. 17)

Ao destacar ações para garantir a permanência das PCD no Ensino Superior, a política indica que as instituições criem condições para tal. Com avanços e retrocessos, a inclusão é processo, é movimento. Por isso, é importante ter clareza de que uma universidade inclusiva se faz no cotidiano e na convivência com as diferenças.

O cenário apresentado até aqui ajuda-nos a compreender a complexidade que é tratar do tema da inclusão no Ensino Superior. Não obstante, encarar essa realidade e promover processos inclusivos no contexto das universidades é tarefa que muitas instituições vêm tomando para si. É nesse contexto que procuraremos contar um pouco da história da UFJF no que se refere à inclusão de PCD.

\section{A Universidade Federal de Juiz de Fora e sua história com a inclusão}

Sabemos que historicamente as universidades se caracterizam como espaços frequentados pela elite da população. Aqueles que conseguem chegar ao Ensino Superior são "os melhores" e mais "capazes". Entretanto, a flexibilização dos processos seletivos e as políticas afirmativas (cotas e reserva de vagas nas universidades) vêm demostrando que esse segmento da educação deixou de ser dirigido a uma elite e passou a ser uma aspiração para os jovens das camadas mais populares.

No que concerne à inclusão das PCD, um importante movimento em prol da permanência desses estudantes nas universidades foi a criação do Programa Incluir. Esse programa teve início em 2005 e voltava-se para o fomento de ações que visavam o pleno acesso das pessoas com deficiência na universidade. Uma das principais ações desse programa foi o incentivo à criação de núcleos de acessibilidade no âmbito das instituições federais de Ensino Superior. Entre os diferentes trabalhos realizados pelos núcleos de acessibilidade, é possível afirmar que o mais importante deles é a construção de estratégias que possibilitem a permanência dos alunos com deficiência na universidade.

A UFJF participou de duas edições do Programa Incluir. Com ações que passaram pela sensibilização da comunidade acadêmica para a questão da inclusão no Ensino Superior e por modificações estruturais no Campus, para melhorar as condições de acessibilidade arquitetônica, o Programa Incluir na UFJF foi um marco histórico, que deu visibilidade aos 
desafios que as PCD enfrentavam no dia a dia para permanecerem na universidade. Uma das ações desse programa foi a criação, no ano de 2009, da Coordenação de Acessibilidade Educacional, Física e Informacional (Caefi). Durante alguns anos, essa coordenação esteve à frente de projetos e ações que visavam possibilitar a permanência dos estudantes com deficiência na UFJF.

Com a mudança de gestão e a necessidade de ações mais efetivas no que tange à inclusão, é criada a Diretoria de Ações Afirmativas (DIAAF), que se trata de um:

[...] setor responsável pela proposição e articulação de ações que sensibilizem e mobilizem a comunidade universitária para a convivência cidadã com as inúmeras realidades presentes na diversidade social, correlacionadas a gêneros e sexualidades, às tradições das culturas, às questões étnico-raciais, à vulnerabilidade socioeconômica, dentre outras. Além disso, a DIAAF mantém uma Ouvidoria Especializada para acolhimento de denúncias e depoimentos a respeito de situações de assédios, discriminações, preconceitos, violências e opressões (UFJF, 2019).

A democratização do acesso ao Ensino Superior, em particular, a chegada dos estudantes com deficiência por meio da política de cotas na UFJF, a partir de 2017, apontou outros rumos para a política institucional. Nesse momento iniciaram-se os debates em torno da extinção da Caefi e da criação de um Núcleo que se responsabilizasse por elaborar uma política de inclusão de PCD para UFJF, dando início à construção de mais um capítulo dessa história.

O NAI foi criado pela Resolução 092/2018, de 23 de agosto de 2018, com o objetivo de articular políticas, práticas e culturas de inclusão e promover a intersetorialidade entre as Pró-Reitorias e Diretorias da UFJF, que já realizavam ações com o propósito de viabilizar o processo de inclusão. A criação do NAI possibilita o planejamento e a execução de um trabalho na área da inclusão no Ensino Superior que vinha sendo executado, porém de forma isolada e fragmentada pela ausência de comunicação e estratégias conjuntas entre os setores, portanto pouco institucionalizadas.

A coordenação do NAI foi confiada a profissionais que atuam com experiência em processos inclusivos em sistemas educacionais. Diferentes setores da universidade vêm pesquisando e desenvolvendo ações no campo da inclusão escolar. Podemos destacar o trabalho realizado pelo Núcleo de Educação Especial (NESP), atualmente conhecido como Núcleo de Estudos e Pesquisas em Educação e Diversidade (Neped), vinculado à Faculdade de Educação. Cumpre mencionar que o Núcleo mobilizador da formação das atuais coordenadoras do NAI, que inspirou profissionais que hoje atuam na educação do município de Juiz de Fora e em outros Estados, tinha como um de seus coordenadores o Professor Carlos 
Alberto Marques, que, além de lecionar as disciplinas voltadas para as questões das deficiências, atuava como pesquisador e se consolidou como referência de superação e luta por uma sociedade e processos educativos mais inclusivos. Mencionamos esse breve histórico para destacar o papel da universidade e de seus atores na formação de profissionais e continuidade de estudos, pesquisas e compromissos voltados para as diversas áreas, em especial aquelas que buscam garantir e efetivar direitos, como é o caso da inclusão em educação.

Nos últimos meses, a UFJF, por meio da Pró-Reitoria de Graduação e da Diretoria de Ações Afirmativas, a qual se vincula ao NAI, tem se empenhado em ampliar o debate sobre a inclusão de PCD por meio de atividades formativas como as rodas de conversa e os seminários formativos. Ainda, os gestores têm buscado realizar uma série de ações que visam garantir um quadro de intérpretes/tradutores de Libras para alunos surdos em sala de aula, como também nas demais atividades e eventos promovidos pela Universidade, assim como a tradução de vídeos institucionais, no sentido de garantir o acesso à comunicação.

O NAI tem utilizado, ainda, a estratégia de realizar reuniões com coordenadores e professores dos diferentes cursos a fim de oferecer suporte e apoio ao processo de inclusão para alunos e professores diante dos novos desafios que são postos pelas diferenças/deficiência.

É importante destacar que o processo de inclusão é contínuo e infindável, necessitando de envolvimento dos coletivos diversos e implementação de projetos que busquem inovar, no sentido de buscar novas estratégias na produção de materiais adaptados e viabilização de maior participação possível dos alunos ingressantes na UFJF na vida universitária.

Dentre os projetos que o NAI vem realizando, optamos por dar destaque neste texto ao mais recente deles e, sem dúvida, o que para nós tem trazido muitos desafios e ao mesmo tempo tem nos revelado o quanto é importante que os estudantes que não possuem uma deficiência se vejam como promotores de ações inclusivas e, com os estudantes com deficiência, construam uma universidade mais inclusiva para todos. Trata-se do projeto experiencial com bolsas de treinamento profissional, para acadêmicos interessados em atuar no acompanhamento pedagógico, assessoramento ao NAI e interpretação e tradução de Libras.

A universidade, como instituição voltada para a produção e disseminação do conhecimento e para a formação técnico-profissional, vem continuamente buscando adaptarse "[...] às circunstâncias e às demandas da sociedade" (ZABALZA, 2007, p. 19) a fim de melhor propiciar aos universitários uma formação consoante às demandas do tempo presente. Nesse sentido, cabe ressaltar que o programa de Treinamento Profissional da UFJF é uma 
estratégia de visa permitir o aperfeiçoamento profissional específico e compatível com a habilitação cursada pelo aluno.

O programa foi oficializado pela Resolução 19, de 2 de julho de 1996. O Programa de Treinamento Profissional da UFJF tem em sua essência propiciar ao acadêmico a oportunidade de colocar em prática e de aprimorar o conjunto de conhecimentos adquiridos ao longo de sua formação nos cursos de graduação. Por meio do acompanhamento de procedimentos relacionados à sua área de formação, o graduando robustece o aprendizado teórico e tem a oportunidade de se aproximar da realidade cotidiana de sua formação profissional por meio da convergência de teoria e prática, vivenciando situações que, por vezes, o conteúdo teórico não abarca.

Outra expectativa do Programa de Treinamento Profissional está vinculada à preocupação que a Universidade tem no momento da transição entre a vida acadêmica dos estudantes e o ambiente profissional, sobre o qual Melo e Borges (2007) salientam que:

[...] a transição da universidade para o mercado de trabalho é uma das trajetórias para os jovens no caminho da construção da vida adulta [...]. Sarriera e Verdin (1996) consideram o período de transição escola-trabalho críticos para o desenvolvimento da juventude, porque certas implicações como a perda da condição de aluno e do apoio da escola, a perda de influência da família, pela necessidade de o indivíduo construir uma identidade própria, a falta do status de trabalhador e do apoio da empresa podem produzir sentimento de impotência, de insegurança, de apatia e de desorganização, e, por conseguinte, de adoecimento, de comportamentos antissociais ou de fuga da realidade, caso o jovem não esteja preparado e apoiado para a aquisição do status de cidadão ativo e produtivo (MELO; BORGES, 2007, p. 383).

Soma-se a esses fundamentos do Treinamento Profissional a preocupação que a gestão do NAI teve de, por meio da seleção de bolsistas para atuação em projetos institucionais para o trabalho com estudantes com deficiência, contribuir, também, com a formação desses jovens graduandos para a cultura da inclusão.

\section{O treinamento profissional no âmbito do NAI e a potencialidade das ações de inclusão com e pelos estudantes}

Como mencionado na primeira seção deste artigo, traremos neste momento algumas reflexões sobre os processos de inclusão na UFJF, destacando-se as falas dos estudantes vinculados ao programa de treinamento profissional.

Para nós foi fundamental conhecer o que os candidatos pensam sobre a inclusão e como se relacionam com essa temática, no âmbito pessoal e profissional. Nesse sentido, ao se 
inscreverem para o edital de seleção, todos elaboraram uma carta de intenção explicitando o porquê de estarem participando desse processo. Tomando por base essas cartas, traremos algumas reflexões pertinentes ao que entendemos ser um dos muitos caminhos para a mudança da cultura institucional em prol da inclusão.

Utilizaremos alguns trechos das cartas de intenção como elementos discursivos importantes para ilustrar a relevância da necessidade de ampliar as práticas inclusivas no interior das universidades e outras instituições de ensino. Os textos dos estudantes revelam aspectos essenciais sobre diferentes nuances da inclusão. Exibem, ainda, elementos para além do interesse específico com a aprendizagem sobre a inclusão, por exemplo, a ansiedade por ser aprovado ou aprovada, por necessitar de apoio financeiro para a continuidade dos seus estudos universitários.

Nesse primeiro edital do Núcleo, foram ofertadas 13 vagas para estudantes interessados em atuar nos projetos desenvolvidos. Nesse primeiro chamamento público, tivemos 47 inscrições de estudantes de diferentes graduações da UFJF. Tal processo, desde a seleção, tem se constituído num ato formativo para todos os envolvidos.

Nas primeiras falas, evidenciamos uma perspectiva de que o processo de inclusão pode promover novas experiências e desafios, que vão desde conviver com as diferenças até a possibilidade de acompanhar a implementação de políticas institucionais de inclusão em educação:

Será um bom desafio que busco alcançar, auxiliar pessoas que terão, suponho, mais ou menos a minha idade e que, também, habitam a UFJF, sob uma perspectiva diferente da minha: o que faz sair da minha "zona de conforto" e buscar romper com as barreiras curriculares e de comunicação, junto com elas $(\mathrm{AB})$.

Acredito que fazendo parte do projeto NAI observarei de perto as políticas institucionais, as articulações promovidas pelo setor, dentre outras práticas organizadas pelo núcleo, promovendo integração, inserção e inclusão. Sendo assim, meu desejo é ajudar essas pessoas que necessitam de assistência, promovendo políticas de ações afirmativas que promovam a igualdade de oportunidade a todas pessoas inseridas no meio acadêmico. Além disso, a inserção do Núcleo de Apoio à Inclusão repercutirá no meu futuro pessoal e profissional, visto que desejo seguir a área de Licenciatura em Artes Visuais, logo, o aprendizado na bolsa será de extremo valor (IM).

A perspectiva assumida pelos dois estudantes supra remete-nos ao conceito tridimensional de inclusão em educação adotado por Booth e Ainscow (2011), que sustentam a ideia de que inclusão se trata de uma articulação entre culturas, políticas e práticas. De acordo com os autores: 
Políticas referem-se a como a instituição é administrada e aos planos de mudanças; práticas têm a ver com o que é aprendido e ensinado e como isso é feito. Culturas refletem as relações e os valores e crenças profundamente enraizados. Mudar as culturas é essencial para que se sustente o desenvolvimento (BOOTH; AINSCOW, 2011, p. 13).

Conforme o referencial mencionado, os excertos a seguir são exemplos de culturas que expressam os valores e crenças que nossos estudantes revelam possuir ao expressarem que:

Acredito que esse treinamento profissional será um marco importante e decisivo tanto em minha vida pessoal quanto na profissional (GR).

Acredito que esse Projeto de Treinamento Profissional me ajudaria efetivamente a levar para além da minha Faculdade os meus anseios futuros, uma vez que vai me ajudar a ter experiência com a área relacionada ao Direito Social, a que eu pretendo seguir como carreira (AF).

Sair do ambiente acadêmico para ter uma relação saudável e consciente com as diferenças dos seres humanos seria um passo importante na minha formação (AC).

Acredito que atuar no NAI deva ser uma experiência enriquecedora, tanto no sentido de estar em contato com outras realidades quanto um aprendizado sobre inclusão. $O$ meu conhecimento sobre inclusão, por conta da minha trajetória e dos vários processos de exclusão das pessoas com deficiência, ainda é pequeno. Ampliar esse conhecimento irá me ajudar tanto pessoal quanto profissionalmente (LP).

Ter esta oportunidade é uma forma de correlacionar a experiência à minha formação e consequentemente me proporcionar a chance de ser um fator contribuinte para que, rompendo as barreiras do preconceito e das limitações, todos os avanços pessoais e sociais sejam apenas uma consequência de um olhar mais atento ao próximo $(A B)$.

O conjunto de expectativas apresentado nos excertos supra revela o desejo de os estudantes terem oportunidade de vivenciar experiências para além das situações acadêmicas, terem contato com outras realidades, contribuírem com colegas que possuam algum tipo de deficiência e, assim, ampliarem o conhecimento sobre inclusão e o processo de formação profissional de modo a agregar elementos. Tais oportunidades formativas certamente os tornarão mais sensíveis às diferenças e às barreiras cotidianas presentes na vida de uma parcela da população, que por longo período esteve alijada de seus direitos.

Essa experiência é potente no sentido de contribuir com a formação de futuros profissionais, que influenciarão outras pessoas e, possivelmente, exercer um papel que amplie o debate nos vários espaços sociais que frequentem, podendo, ainda, minimizar a tensão 
oriunda no momento de transição do ambiente acadêmico para o mercado de trabalho, favorecendo a adaptação do estudante ao novo contexto de atividade laboral.

Como veremos a seguir, outros fatores influenciaram os estudantes participantes do processo de seleção para bolsista de treinamento:

Desejo participar do projeto em questão, pois acredito que minha trajetória até aqui mostra um pouco do quanto esse desejo por amenizar as desigualdades e produzir um país mais inclusivo às minorias é pulsante em minha vida. Com a conjuntura política atual, as pessoas precisam ser incluídas cada vez mais, pois é um direito delas própria de terem as mesmas condições de relação com a sociedade (ML).

Cresci e me envolvi ao longo do meu crescimento acadêmico com pautas que dizem respeito à inclusão, seja ela no recorte racial, de gênero, de classe, e mais recentemente de pessoas com necessidades especiais. Com pai professor do Município e do Estado e com mãe e irmã Assistentes Sociais e militantes da Luta antimanicomial e de inclusão de pessoas com transtornos mentais, sempre tive contato com tais pautas. Mais recentemente, com mãe diagnosticada Deficiente Auditiva, além de Intérprete e Professora da Lingua Brasileira de Sinais, me vejo mais perto e mais inserida nesta causa, mas ainda necessito de mais conhecimentos e vivências na área, que vem despertando meu interesse (NM).

No projeto que já faço parte vamos às escolas de nível infantil, fundamental e médio para observarmos a rotina das salas de aulas com crianças com TEA e depois propor atividades inclusivas, o que é uma experiência extremamente humanizadora e de aprendizagem. Em nossas reuniões semanais discutimos temas relacionados à inclusão, à dificuldade que escolas, professores e famílias encontram para tornar o mundo um lugar mais justo para todos e também sobre as conquistas que alcançamos no mundo inclusivo (JM).

É perceptível que alguns estudantes já estão engajados em questões sociais e pautas políticas que visam ampliar e garantir direitos para todos. A inclusão nas falas supra tem sido uma preocupação e uma vivência cotidiana para alguns de nossos bolsistas. Certamente, tais experiências repercutirão positivamente no processo de implementação das culturas, políticas e práticas de inclusão, visto que o intercâmbio de saberes e práticas colaborativas são princípios importantes para esse processo.

Para efeito desse relato de experiência, elencamos apenas as falas dos bolsistas selecionados. Entretanto, vale ressaltar que tivemos contato com outros textos que expressam intenções positivas com relação ao processo de inclusão no ensino superior.

As falas a seguir destacam o papel social da universidade e a necessidade de se ajustar às demandas emergentes: 
Vivemos em um século em que a sociedade se avança em diversos aspectos, e é extremamente necessário que as escolas e faculdades acompanhem essas evoluções e transformações (PM).

A universidade pública é um lugar de todos e, sendo assim, todos devem se sentir parte dela $(\mathrm{BB})$.

Os bolsistas têm se empenhado em pensar as tarefas a serem cumpridas para ampliar o processo de inclusão na UFJF e de auxiliar os alunos com deficiência em suas tarefas acadêmicas. $\mathrm{O}$ trabalho tem sido construído gradativamente, a partir da identificação dos estudantes e de suas necessidades especiais.

O desejo de auxiliar o trabalho da universidade no cumprimento desse papel tem sido compartilhado também por outros vários atores da comunidade acadêmica: gestores, professores, técnicos administrativos e terceirizados. Entretanto, inclusão não se faz apenas com intenção, exige mudanças, recursos e colaboração entre todos. Não pode ser considerado um processo sob responsabilidade de determinados atores. TODOS têm um papel importante e precisam colaborar individualmente para que ações coletivas sejam debatidas e efetivadas.

Podemos inferir a partir das falas apresentadas que existe entre os estudantes uma enorme vontade de promover mudanças, em particular no que se refere às culturas e práticas de inclusão no lugar onde estudam e se preparam para uma carreira profissional. Todos trazem um sentido positivo para o convívio com as diferenças e, ao mesmo tempo, demonstram que, a partir de uma mudança atitudinal, a sociedade e, em particular, a UFJF caminharão para se tornarem um espaço cada vez mais democrático e inclusivo.

É importante dizer que as experiências vivenciadas por esses estudantes nesse projeto têm um grande potencial transformador não somente para a formação acadêmica, mas, sobretudo, para a formação profissional. Oriundos de diferentes cursos de graduação da UFJF, cada um desses jovens relaciona as experiências do projeto com suas carreiras futuras, demonstrando o quanto é necessário que ocorram avanços em diferentes áreas do conhecimento e da profissão para que as PCD sejam mais bem atendidas ou tenham maior autonomia para fazer suas escolhas profissionais e de vida. Estamos aprendendo juntos.

\section{Últimas considerações}

Sem a pretensão de sermos conclusivos, o que podemos apresentar como reflexões a partir da experiência relatada é que, mesmo com um grande caminho já percorrido pela sociedade brasileira, especialmente do ponto de vista legal, os desafios presentes no que tange à promoção da inclusão educacional de PCD no Ensino Superior ainda são grandes. 
Como apresentamos na primeira seção deste artigo, as universidades têm vivenciado com mais ênfase a presença de estudantes com deficiência no seu interior após a criação das políticas de ações afirmativas, nesse caso, da Lei 13.409/2016. Vale lembrar que algumas instituições de Ensino Superior, antes mesmo da citada lei, adotavam políticas de ações afirmativas de ingresso destinadas a candidatos de escolas públicas, pretos e pardos, indígenas e/ou PCD. A Universidade do Estado do Rio de Janeiro (UERJ), em 2002, foi a primeira instituição a garantir o sistema de vagas no seu vestibular (CABRAL, 2018).

Com as iniciativas legais de ampliação do acesso de PCD no Ensino Superior e a chegada dessas pessoas à universidade, emergem nesse contexto situações que nos levam a compreender o quanto é necessário que, nesse segmento de ensino, ocorram mudanças para que as políticas, culturas e práticas institucionais passem a considerar as especificidades das PCD. Tais mudanças passam por diferentes níveis, da gestão institucional até às salas de aula, nas políticas de pesquisa e extensão, nas modificações estruturais e arquitetônicas, na promoção de acessibilidade informacional e comunicacional, entre muitas outras.

O tempo presente com suas contínuas e aceleradas mudanças trazem diferentes demandas formativas aos estudantes da graduação. O trabalho com a inclusão de PCD nas universidades contribui para a compreensão de que a diversidade é uma construção social e deve constituir-se em currículos de formação da graduação, consoante com essas exigências da contemporaneidade. Por meio das bolsas de TP e outras experiências formativas que o NAI tem proposto, a formação acadêmica e profissional dos graduandos vai se enriquecendo com esses conteúdos, promovendo inclusão.

Importante chamar atenção para uma mudança em especial que se relaciona diretamente com as possibilidades de permanência e participação dos estudantes com deficiência: as mudanças e adaptações das práticas pedagógicas. Promover ações de formação continuada e criar serviços de apoio aos professores na sua prática cotidiana é fator essencial para que as questões que emergem na prática desses sujeitos sejam refletidas e resolvidas de forma a garantir que os estudantes com deficiência consigam participar dos processos acadêmicos com qualidade.

No tocante à permanência e participação, podemos concluir que, na UFJF, o trabalho do NAI, na lógica da intersetorialidade, tem nos mostrado que, para uma efetiva mudança da cultura institucional, todos os setores da Universidade devem estar envolvidos. Nesse sentido, temos promovido ações que não se restringem ao aspecto pedagógico, mas abrange, também, ações no campo da política e da responsabilização de todos com relação ao seu papel do que estamos chamando de promotores da inclusão. Isso envolve diretamente os gestores, técnicos administrativos, docentes, funcionários terceirizados e estudantes. 
Barreiras precisam ser vencidas no sentido de garantir a emergência de culturas, políticas e práticas de inclusão que favoreçam encontros com as diferenças; possibilitem relações colaborativas entre os diferentes atores; promovam a intersetorialidade e a circulação de informações; e se consolidem como princípios não fixados apenas em cumprimentos de lei, mas como processo irrevogável e como compromisso que toda instituição precisa consolidar.

\section{REFERÊNCIAS}

BOOTH, T; AINSCOW, M. Index para inclusão: desenvolvendo a aprendizagem e a participação na escola. Tradução Mônica Pereira dos Santos, PHD. 3. ed. Rio de Janeiro: LaPEADE, 2011.

BRASIL. Ministério da Educação. Política Nacional de Educação Especial na perspectiva da Educação Inclusiva. MEC; SEEP; 2008.

CABRAL, L. S. A. Políticas de ações afirmativas, pessoas com deficiência e o reconhecimento das identidades e diferenças no ensino superior brasileiro. Arquivos Analíticos de Políticas Educativas, v. 26, n. 57, abr. 2018.

CABRAL, L. S. A.; MELO, F. R. L. V. Entre a normatização e a legitimação do acesso, participação e formação do público-alvo da educação especial em instituições de ensino superior brasileiras. Educar em Revista, Curitiba, v. 33, número especial, p. 55-70, dez. 2017.

MATOLA, P. U. O desenvolvimento de competências profissionais em projetos de treinamento profissional do Centro de Biologia da Reprodução da Universidade Federal de Juiz de Fora como contribuição para a formação do graduando. 2015. Dissertação (Mestrado) - Programa de Pós-Graduação Profissional em Gestão e Avaliação da Educação Pública (PPGP), Universidade Federal de Juiz de Fora, Juiz de Fora, 2015.

MELO, S. L.; BORGES, L. O. A transição da universidade ao mercado de trabalho na ótica do jovem. Psicologia, Ciência e Profissão, v. 27, n. 3, p. 376-395, 2007. Disponível em: http://www.scielo.br/scielo.php?pid=S141498932007000300002\&script=sci_abstract\&tlng=pt. Acesso em: 14 maio 2019.

UFJF. Diretoria de Ações Afirmativas. Disponível em: https://www.ufjf.br/diaaf/. Acesso em: 16 maio 2019.

ZABALZA, M. A. O ensino universitário: seu cenário e seus protagonistas. Porto Alegre: Artmed, 2007.

Como referenciar este artigo

AMORIM, Cassiano Caon; ANTUNES, Katiuscia C. Vargas; SANTIAGO, Mylene Cristina. Inclusão no ensino superior: um processo em pauta na universidade federal de Juiz de Fora UFJF. Doxa: Rev. Bras. Psico. e Educ., Araraquara, v. 21, n. 2, p. 334-348, jul./dez. 2019. eISSN: 2594-8385. DOI: https://doi.org/10.30715/doxa.v21i2.13104 
Submetido em: 20/02/2019

Aprovado em: 20/07/2019

Publicado em: 01/08/2019

Doxa: Rev. Bras. Psico. e Educ., Araraquara, v. 21, n. 2, p. 334-348, jul./dez. 2019 